available and social demand. Therefore, in contrast with US students, who are guaranteed a psychiatry position, Spanish medical students may regard psychiatry as a more worthwhile specialty because of the competition for training places.

From the 1950s to the mid-1970s, studies in the U nited States showed that students considered psychiatry more unscientific and imprecise and to have less prestige than nowadays. How ever, recruitment then was at its highest (C astelnuovo-Tedesco, 1967; Zimet $\&$ H eld, 1975). Students seemed to make their choice while being very aware of the specialty's weak points. Paradoxically, when students' opinions are more critical, recruitment in both Spain and the U nited States seems to rise, probably because being more critical leads to a better understanding and stronger desire to choose the specialty. $0 \mathrm{r}$ could it be that recruitment has nothing to do with attitudes to psychiatry after all?

\section{References}

Balon, R., Franchini, G. R., Freeman, P. S., et al (1999) Medical students' attitudes and views of psychiatry: 15 years later. Academic Psychiatry, 23, 30-36.

Brockington, I. F. \& Mumford, D. B. (2002) Recruitment into psychiatry. British Journal of Psychiatry, 180, 307-312.

Castelnuovo-Tedesco, P. (1967) How much psychiatry are medical students really learning? Archives of General Psychiatry, 16, 668-675.
Feifel, D., Moutier, C. Y. \& Swerdlow, N. R. (1999) Attitudes toward psychiatry as a prospective career among students entering medical school. American Journal of Psychiatry, 156, 1397-1402.

Lee, E. K., Kaltreider, N. \& Crouch, J. (1995) Pilot study of current factors influencing the choice of psychiatry as a specialty. American Journal of Psychiatry, 152, 10661069

National Resident Matching Program (2003) Match Results, 1999-2003. Washington, DC: N ational Residents Matching Program. See http://www.nrmp.org/. Last accessed 26 August 2005.

$\mathrm{N}$ ielsen, A. C. 3rd \& Eaton, J. S. Jr (1981) Medical students' attitudes about psychiatry. Implications for psychiatric recruitment. Archives of General Psychiatry, 38, 1144-1154.

Pailhez, G., Bulbena, A., Coll, J., et al (2005) Attitudes and views on psychiatry: a comparison between Spanish and U.S. medical students. Academic Psychiatry, 29, 82-91.

Sierles, F. (1982) Medical school factors and career choice of psychiatry. American Journal of Psychiatry, 139, 1040-1042.

Sierles, F. S. \& Taylor, M. A. (1995) Decline of US medical student career choice of psychiatry and what to do about it. American Journal of Psychiatry, 152, 1416-1426.

Sierles, F. S., Dinwiddie, S. H., Patroi, D., et al (2003a) Factors affecting medical student career choice of psychiatry from 1999 to 2001. Academic Psychiatry, 27, 260-268.

Sierles, F. S., Yager, J. \& Weissman, S. H. (2003b) Recruitment of U.S. medical graduates into psychiatry: reasons for optimism, sources of concern. Academic Psychiatry, 27 $252-259$

Singh, S. P., Baxter, H., Standen, P., et al (1998) Changing the attitudes of 'tomorrow's doctors' towards mental illness and psychiatry: a comparison of two teaching methods. Medical Education, 32, 115-120.

Zimet, C. N . \& Held, M. L. (1975) The development of views of specialties during four years of medical school. Journal of Medical Education, 50, 157-166.

\title{
Some Australian reflections on problems with recruitment into the profession of psychiatry
}

\author{
Bruce J. Tonge
}

Professor and Head, Department of Psychological Medicine, Monash University, Monash Medical Centre, Clayton, Victoria 3168, Australia, email: bruce.tonge@med.monash.edu.au

Both studies found that psychiatry was regarded overall as the least attractive career option in the field of medicine and that the students held negative and prejudicial views about the practice of psychiatry and its patients. sychiatry has probably always been the least attractive of the medical specialties. The choice of psychiatry as a career has been consistently low in the English-speaking world over the past 50 years (British Medical Journal, 1973; Feifel et al, 1999; Brockington \& Mumford, 2002). O ver the past decade there has probably been a further decline in the proportion of medical graduates choosing to train in psychiatry (Sierles \& Taylor, 1995; Feifel et al, 1999).

\section{The situation in Australia: an international comparison}

In Australia over the past several years it has been increasingly difficult to fill available psychiatry training positions. A critical factor in recruitment is the attitude medical students develop towards psychiatry as a specialty and as a possible career choice.

In 2003 an Australian study was published regarding the attitudes of 655 new medical students towards psychiatry as a career choice (Malhi et al, 2003). This study replicated the findings of a study of 221 new students attending three medical colleges in the southwest U nited States (Feifel et al, 1999). Both studies found that psychiatry was regarded overall as the least attractive career option in the field of medicine and that the students held negative and prejudicial views about the practice of psychiatry and its patients.

The Australian study gathered questionnaire information from 655 , of a possible 1032 , first-year medical students attending a mix of six undergraduate-entry 
( $n=452)$ and graduate-entry $(n=203)$ medical schools (Malhi et al, 2003). The questionnaire from the US study, with minor modification, was used in the Australian study. Student attitudes were compared regarding careers in medicine, surgery, paediatrics, general practice, obstetrics and gynaecology and psychiatry.

The Australian findings point to a number of student perceptions which probably contribute to the unattractiveness of psychiatry as a profession:

- Financial reward. Psychiatry rated slightly ahead of general practice but behind the other specialties.

- Job satisfaction and enjoyable work. Psychiatry was rated the lowest of all specialties.

- Lifestyle. 0 bstetrics and gynaecology and surgery were rated lower than psychiatry. The US students rated lifestyle as significantly more attractive than the Australian students.

- Interest and intellectual challenge. Psychiatry rated ahead of obstetrics and gynaecology and general practice.

- Scientific foundation and drawing on all aspects of medicine. Psychiatry rated the lowest.

- Effective and helpful treatments. Psychiatry was viewed as having the least effective treatments.

- Prestige and association with colleagues. Psychiatry was rated the lowest. The students also considered that psychiatry would be held in the lowest regard by their families and other students but considered that other physicians might rank general practice lower than psychiatry.

In spite of these attitudes, $15.9 \%$ of the Australian students indicated that the choice of psychiatry as a career was 'a strong possibility', which must be regarded as something for the profession to build on during the medical course. In the US study only $7.7 \%$ of the students no minated a career in psychiatry as at least 'a strong possibility'.

\section{Improving recruitment}

These findings paint a pessimistic picture for recruitment but also point to strategies for improving the attractiveness of psychiatry. Competitive increases in the financial remuneration of psychiatrists in both the public and private health sectors in Australia are central to better recruitment. This requires a political decision, not just about the budget allocated to mental health services but also about the necessary numbers of psychiatrists per head of population.

Recruitment is unlikely to improve unless working conditions and job satisfaction improve. Patients in public mental health services are serio usly mentally ill, often with a complex of psychosis, personality disorder and substance misuse problems. The Australian medical students expressed concern that psychiatrists experienced personal danger and emotional stress in their work environment. Flexible employment conditions which provide the possibility of a variety of clinical roles, options to undertake some research or teaching and adequate support for professional development may help to improve job satisfaction.

The recognition by medical students that psychiatry is interesting and intellectually challenging is a perception to build upon. The challenge to curriculum design is to ensure that students learn about:

- the exciting and rapidly expanding scientific basis of psychiatry

- the relative effectiveness and range of treatments of psychopathology

- the richness of a bio-psychosocial model in understanding human development, behaviour, health and illness

- the enthusiasm of psychiatrists for their work. Although competitive high achievement, usually in mathematics and the sciences, determines entry into undergraduate and graduate medical courses in Australia, all courses have interview or other selection processes which favour students with better communication and interpersonal skills. Psychiatry staff also teach about the psychological system in the classes on clinical skills and professional attitudes that are now components of all medical courses in Australia.

The pervasive negative community attitudes and stigma towards individuals with mental illness extend to psychiatrists and other mental health professionals (Sartorius, 1998). This community apprehension about mental illness is likely to colour medical students' and even other medical practitioners' perceptions of psychiatrists.

Public mental health promotion campaigns and efforts over the past decade by government agencies and professional organisations in Australia have focused on reducing the stigma and community fear of mental illness. The continuation of vigo rous efforts to reduce the stigma associated with mental illness coupled with further advances regarding brain function and the treatment of psychopathology are likely to improve attitudes tow ards psychiatry and improve recruitment.

\section{References}

British Medical Journal (1973) Not so popular psychiatry. British Medical Journal, i, 435-436.

Brockington, I. F. \& Mumford, D. B. (2002) Recruitment into psychiatry. British Journal of Psychiatry, 180, 307-312.

Feifel, D., Moutier, C. Y. \& Swerdlow, N. R. (1999) Attitudes toward psychiatry as a prospective career among students entering medical school. American Journal of Psychiatry, 156, 1397-1402.

Malhi, G. S., Parker, G. B., Parker, K., et al (2003) Attitudes towards psychiatry among students entering medical school. Acta Psychiatrica Scandinavica, 107, 424-429.

Sartorius, N. (1998) Stigma: what can psychiatrists do about it? Lancet, 352, 1058-1059.

Sierles, F. S. \& Taylor, M. A. (1995) Decline of US medical student career choice of psychiatry and what to do about it. American Journal of Psychiatry, 152, 1416-1426.
The Australian

medical students expressed concern

that psychiatrists experienced

personal danger and emotional stress in their work

environment.

Community apprehension about mental illness is likely to colour medical students' and even other medical practitioners' perceptions of psychiatrists. 